\title{
Internet Financial Risk Supervision and Countermeasures
}

\author{
Hua Xiang and Tao Yongchao \\ Dongchang College of Liaocheng University \\ Shandona Academv of Social Sciences
}

Keywords: Financial Risk, Risk Regulation, Supervision Standards, Internet Financial Platform

\begin{abstract}
At present, the development of Internet finance in China is still in its infancy, and there are still many gaps in the regulation of Internet financial risks. In addition to the risks of traditional finance, Internet finance also faces the risks brought by the Internet itself, which also makes it more difficult to supervise. We can improve the countermeasures of Internet financial regulation from the aspects of supervision standard, subject of supervision, risk early warning and supervision evaluation.
\end{abstract}

\section{Introduction}

According to industry statistics, the number of investors and borrowers reached 13.75 million and 8.76 million respectively. It increased by $134.64 \%$ and $207.37 \%$ respectively from 2015 . Compared to traditional financial industry, as a beneficial supplement of the current financial system ,the Internet finance has the advantages of the convenience, high efficiency, it not only plays a positive role in daily pay, investment activities, but also plays an important role in changing the small and medium-sized enterprises financing difficulties, broadening the financing channels, improving the efficiency of capital allocation and so on. In addition, with the increase of national income and the awakening of financial consciousness and bank interest rates failing to keep pace with inflation and the depreciation of deposits, the public began to look for investment platforms with higher returns for idle funds.

However, the rapid rise of Internet financial platforms represented by P2P lending platforms, crowdfunding platforms and third-party payment platforms provides a new direction for social idle funds. Especially its high benefits just meet the demand of the new demand of the mass group. However, behind the promise of high returns and low risk, the hidden risks are also emerging. Under the premise that the number of normal operating platforms has declined, the number of problem platforms has soared, and the lack of supervision and guidance of Internet finance has caused the industry to fall into "abnormal". Especially the instantaneous collapse of the Internet financial platform, which has been positively appraised by many parties, such as ezubao and rijinbao, triggered a chain reaction, it not only makes many investors suffer huge losses, but also the stampede caused by investor panic overwhelmed many of the compliance platforms. The entire Internet banking industry is in a crisis of confidence.

\section{The Current Situation of Internet Financial Risk Supervision}

\section{Lack of Supervision Standards.}

For the traditional financial industry, the state has promulgated the "law of the people's bank of China", the securities law and the insurance law to guide it. There are three supervisory bodies of the CBRC, the insurance regulatory commission and the CSRC to supervise the operation and transaction records of the traditional finance, insurance and stock market. And internet technology spreads to a wide range, high popularity, transmission speed, strong and cross characteristics determine the Internet financial risk is different from the traditional financial, Therefore, it is not easy to effectively supervise Internet financial risks. Although the central bank has already noted that the huge amount of money held by third-party payment platforms represented by alipay and WeChat is in a regulatory gap, and successively promulgated rules and regulations such as"the 
non-financial payment services management method " "interim measures for the depository of payment institution customers" and "payment agency Internet payment business management guidelines" and so on to guide its normal development .However, with the continuous expansion of the third-party payment platform business, its service function has far exceeded the positioning of payment intermediary, It also extends to investment banking, middle and small loan financing, insurance fund and other fields. There is still no clear supervision standard for the extended services provided by the Internet financial platforms.

\section{The Attribution of Supervisory Responsibilities is Difficult to Define.}

In addition to the lack of regulatory standards, there is another reason to make Internet financial regulation more difficult. That is Who is responsible for supervision? Internet financial products involve both bank financing, fund, insurance and precious metals investment, as well as information security. The diversification of its business operation determines the diversification of the subject of supervision. For example, the CBRC and the CIRC have supervisory responsibilities over the financial and insurance services provided by Internet finance. The information security of the Internet financial platform should be supervised by the ministry of industry and information technology and the public security department. The overlapping supervision of multiple departments makes the functions of various departments vague, there is no clear distinction and supervision assistance mechanism, which ultimately leads to the lack of unified regulatory bodies in the industry.

\section{Backwardness of Regulatory Means.}

Internet finance is a financial service based on Internet technology. It relies on big data, cloud computing and data sharing to continuously expand the scope and content of financial services. The openness and sharing of internet makes it vulnerable to security risk. In a sense, the healthy and sustainable development of the Internet finance industry depends not only on the operation effectiveness of external supervision mechanism. It depends more on the perfection of the risk prevention mechanism. In addition, the huge transaction data accumulated by Internet finance is stored in magnetic media in paperless electronic data, which provides opportunities to delete or modify transaction data for those who have no access data. And the change of electronic data leaves no trace, there is no trace of fraud. Therefore, any illegal access or contact behavior will affect the integrity and authenticity of the transaction data of the financial platform, thus increasing the operational risk of the platform. The high virtualization of Internet financial transactions puts forward higher regulatory requirements for the subject of supervision, forcing regulators to constantly improve the means and methods of regulation and pay more attention to the reserve and cultivation of professional supervisors to adapt to the new environment of regulatory requirements.

\section{There are Loopholes in Regulatory Policies and Measures.}

Although relevant supervision bodies have adopted policies such as "the non-financial payment services management method " "interim measures for the depository of payment institution customers on precipitation funds of Internet financial platforms to guide the development of industry compliance. However, compared with the development speed of Internet finance industry, the policy guidance of the regulatory body is particularly lagging. Especially when the third-party payment platform generally extends the function of payment intermediary to investment banking, fund insurance and microcredit, the regulator has not issued policy documents in time to guide them according to the real development needs of the Internet finance industry, making some of the business and funds of the platform outside of supervision

\section{Countermeasures and Suggestions on Internet Financial Risk Supervision}

\section{Improve the Internet Financial Risk Supervision Standards.}

In the face of the lack of laws and regulations on Internet financial supervision in China, the legislative branch should take the lead in improving the legal and regulatory system of Internet financial regulation and provide the basis and regulatory standards for Internet financial innovation supervision. Under the existing laws and regulations of financial supervision, combining with the reality of the development of Internet finance, it is necessary to make up the regulatory loopholes 
existing in the supervision of Internet finance supervision by the current regulatory bodies. Especially for Internet financial innovation business, such as crowd-funding, P2P internet financing, etc., we should issue the official legal regulatory standards to guide the healthy development of industry, which can also provide the basis for regulatory implementation industry regulations. At the same time, the internal innovation of Internet finance should be considered reasonably in the process of legislation. On the one hand, we should prevent the legislation from being too strict or too conservative, which will restrain the vitality and innovation impetus of Internet finance development. On the other hand, we must combine the pace of Internet financial development to make up for the loopholes and gaps in time. Especially the business with strong intersections and complex types should have clear regulatory standards and to prevent financial risks effectively.

Clarify the Subject of Supervision and the Allocation of its Rights and Responsibilities.

In view of the difficulty in defining the subject of Internet financial supervision, we should draw on the supervision pattern of traditional financial supervision "one line three meeting" Under the current supervision law system, we should make responsibilities of each supervisor clear to solve the problems such as repeated supervision and unclear responsibilities. For example, we can draw lessons from the unified supervision mode of the people's bank of China implemented in the early stage of China's financial supervision. The management division of the bank division, the division, the non-bank financial institutions, the insurance division and the foreign financial institutions shall be responsible for the specific regulatory responsibilities of each business. Finally, the report system, annual inspection system, rating system and other issues should be reported to the people's bank of China for supervision. The supervision mode of unified supervision "commander" and business division cooperation of each level, collaborative division of labor can effectively solve the realistic problems such as repeated supervision and unclear supervision responsibilities. However, the current separation of supervision mode causes all levels of supervision to be parallel to each other, the lack of unified supervision of "commanders" can easily lead to the evasion and dispute. Therefore, to prevent the "kick ball" strange phenomenon. We should also establish the coordination and cooperation mechanism between the various regulatory bodies to clarify the various business boundaries of Internet finance from the content first. Then we should formulate specific regulations to clarify the scope and contents of supervision. The difficulties of supervision of the Internet financial risk are difficult to grasp how to maintain the balance of the innovation and regulatory supervision division of labor, how to coordinate the supervision capacity of each regulatory body, how to break through the supervision and guidance of industry supervision technology, how to realize strengthening the cooperation and coordination between the regulatory bodies in advance and in the process, to improve the regulatory efficiency through the formation of the Internet financial comprehensive supervision mechanism.

\section{Establish a Risk Warning System Based on Big Data.}

Regarding the problem of the Internet financial regulation means backwardness, the relevant regulatory body should innovative means of regulation, and try to establish risk warning system based on big data, to strengthen the risk control of the financial industry. Big data analysis can meet the processing and analysis needs of the current mass data with the help of Internet, Internet of things and human-computer interaction. As the representative of emerging finance, Internet finance needs not only to clear the internal development status through big data analysis, but also to warn the existing risks based on big data analysis results. This provides an advanced means for regulators to use big data analysis tools to strengthen the risk supervision of Internet finance. As Internet finance can generate huge data information, the subject of supervision can collect and summarize transaction data through unified collection. Perfect dynamic database should be established under the precondition of unified data format, Then, the data analysis model, risk identification model and risk warning model of the big data analysis center in the background are used to carry out real-time monitoring of Internet financial online transaction records and information, making corresponding risk warning report, the relevant regulatory bodies can understand the overall risk status of the industry through the early-warning report formed by the system, which also provides the direction for the following clear regulatory focus and the completion of risk management. 


\section{Establish a Differentiated Regulatory Assessment System.}

Regarding the problem of loopholes in Internet financial regulation policies and measures, we can use the rating system formed by traditional financial institutions to effectively rate the risk supervision status of different operating platforms on the base of improving the credit system. The traditional financial regulation has formed a relatively perfect rating system, but as an emerging industry Internet finance lacks special regulators.to evaluate it. Therefore, the industry is mixed with different persons and the platform quality is uneven. The explosion of platform scandals is the result of the lack of the industry's regulatory assessment system, which has been successful in taking investors' money away and bringing a negative reputation to the industry. Therefore, we can try to imitate the rating system of traditional financial institutions and carry out regulatory evaluation on different business operations of Internet financial institutions.

First, internet financial institutions have abilities to establish credit system gradually based on cloud computing and other information technologies. The credit risk is evaluated by means of big data to control the credit risk and form a unified credit rating system. According to the actual situation of the Internet financial markets, we should strengthen the monitoring of credit risk to effectively curb the risk brought by Internet financial innovation through the different index system construction of risk early warning mechanism, However, the subject of supervision should break the imbalance between the government-led credit system and the private credit development, to promote the coordinated development of and increase control of the credit risk by the subject of supervision.

Second, try to follow the traditional financial institutions' rating system and conduct regulatory assessment on different business operations of Internet financial institutions, to form differentiated evaluation systems for third-party payment platform, P2P online lending platform, Internet financial management platform, objectively and fairly reflect the current situation of risk supervision of different operating platforms in Internet financial environment. The establishment of differentiated supervision and evaluation system also provides favorable conditions for regulators to make up for regulatory policies and loopholes and improve supervision ability.

\section{Reference}

[1] Zhong chenglin. financing difficulties for small and medium-sized technology-based enterprises and Financial support policy research[J].Journal of Nanjing University of audit,2016(3).

[2] Huang wenyan Duan wenqi. internet finance: risk supervision and development[J].Shanghai economic research,2015(8)

[3] Miao wenlong. internet payment: finance risk and supervision design[J].Modern finance and economics,2015(2)

[4] Hong juan, Cao bing, Li xin. Research on the particularity of Internet financial risk and its supervision strategy[J]. Journal of central university of finance and economics,2014(9).

[5] Wei peng. Research on the risk and supervision of Internet finance in China[J]. Finance Forum ,2014(7).

[6] $\mathrm{Yu}$ D, Peng L. When does Inferring Reputation Probability Countervail Temptation in Cooperative Behaviors for the Prisoners' Dilemma Game? [J]. Chaos, Solitons \& Fractals, 2015, 78: 238-244. 